\title{
Migration law of flax threshing materials in double channel air-and-screen separating cleaner
}

\author{
Fei Dai ${ }^{1}$, Xuefeng Song ${ }^{1}$, Ruijie Shi ${ }^{1}$, Wuyun Zhao ${ }^{1 *}$, Wenjuan Guo ${ }^{1,2}$, Yang Zhang ${ }^{1}$ \\ (1. College of Mechanical and Electrical Engineering, Gansu Agricultural University, Lanzhou 730070, China; \\ 2. School of Cyber Security, Gansu University of Political Science and Law, Lanzhou 730070, China)
}

\begin{abstract}
In order to further clarify and improve the working performance of separating cleaner for flax threshing materials, and study the migration law and characteristics of components of flax threshing materials during separating and cleaning, in this paper, a gas-solid coupling simulation model was established on the separation cleaner for flax threshing materials and a numerical simulation was carried out on the separating and cleaning process. Simulation results showed that, the separating and cleaning effect of the components of flax threshing materials was good under the air-and-screen gas-solid coupling flow field. Meanwhile, the form distribution and the vector distribution of air volume and velocity of flax threshing materials in the air-and-screen devices were obtained. By referring to the migration trajectories of the flax threshing materials in the vibration sieve device, double channel residue collection device and dust absorber, the volume variation, motion trajectories and variation of migration velocity of the components of flax threshing materials over time in different regions were explored. Verification test results showed that, the content impurity rate of the separation cleaner for flax threshing materials was $2.06 \%$, and loss rate in cleaning was $3.08 \%$. Compared with simulation results, the verification test results were $1.23 \%$ and $0.42 \%$ higher, showing that the established discrete element model on the flax threshing materials and parameter setting were basically feasible. The verification test also verified the correctness of the simulation results of the separating and cleaning process of the flax threshing materials based on gas-solid coupling theory and the feasibility of the research method.
\end{abstract}

Keywords: flax threshing materials, separation cleaner, air-and-screen, gas-solid coupling, discrete element model, numerical simulation

DOI: $10.25165 /$ j.ijabe.20211403.6058

Citation: Dai F, Song X F, Shi R J, Zhao W Y, Guo W J, Zhang Y. Migration law of flax threshing materials in double channel air-and-screen separating cleaner. Int J Agric \& Biol Eng, 2021; 14(3): 92-102.

\section{Introduction}

The migration of agricultural material flow in separating cleaner is a complicated process of two-phase flow, where there are both effect of solid phase on solid phase and gas phase to solid phase ${ }^{[1,2]}$. The study of migration law of threshing materials in the separating and cleaning process not only helps to reveal the working principle of the device, but also further optimizes structure of the device and eliminates the vortex flow field within the cleaning chamber, marking it significant in improving the working performance of separating cleaners for agricultural threshing materials $^{[3,4]}$.

In recent years, there are abundant studies on the threshing and transmission principles, migration law and separating and cleaning properties of agricultural material flow, which have become the research focus in the field of mechanized harvesting of crops.

\section{Received date: 2020-07-31 Accepted date: 2021-01-19}

Biographies: Fei Dai, PhD, Associate Professor, research interests: design of agricultural mechanization equipment, Email: daifei@gsau.edu.cn; Xuefeng Song, Lecturer, research interests: agricultural mechanization engineering, Email: 549349477@qq.com; Ruijie Shi, PhD candidate, research interests: agricultural mechanization engineering, Email: 1139230110@qq.com; Wenjuan Guo, PhD candidate, research interests: computer simulation, Email: 565105996@qq.com; Yang Zhang, PhD, Lecturer, research interests: agricultural mechanization engineering, Email: zy3537@qq.com.

*Corresponding author: Wuyun Zhao, $\mathrm{PhD}$, Professor, research interests: farm machine and mechanical reliability. College of Mechanical and Electrical Engineering, Gansu Agricultural University, Lanzhou 730070, China. Tel: +86-451-7632472, Email: zhaowy@gsau.edu.cn.
Among them, Li et al. utilized the Computational Fluid DynamicsDiscrete Element Method (CFD-DEM) to study motion law and velocity of rice grains and stalks on single-layer vibration sieve, and proved the feasibility of this research method ${ }^{[2]}$; Cleary et al. simulated the screening process of 8000 particles with particle size of $10-80 \mathrm{~mm}^{[5]}$; Wang et al. applied gas-solid coupling theory to reveal the motion law of threshed material of corn in the double-layer cross air-and-screen cleaner and acquired the method of adjusting the working parameters to improve the grain cleaning rate $^{[1,6]}$. Mekonnen et al. ${ }^{[7]}$ applied the method of computational fluid mechanics to study the effect of different positions of vortex wall on the horizontal axial flow distribution of grain combine harvester; Jiang et al. ${ }^{[8]}$ simulated the motion law of grains in the separation chamber of the combine harvester and carried out tests based on CFD-DEM coupling, and explored the effective method of improving the preliminary grain cleaning performance of the separating chamber.

At present, the separation and cleaning of flax threshing materials is mainly carried out with the equipment of rice and wheat separation and cleaning, so there is no equipment specially suitable for the separation and cleaning of flax threshing materials. In view of the little difference of components of flax threshing material, which have high impurity rate and cause serious loss in separation and cleaning ${ }^{[4]}$, the double channel air-and-screen separating cleaner for flax threshing material based on two-stage harvesting need to be further studied ${ }^{[9]}$. Meanwhile, since there are few studies on the three-layer screening of agricultural material particle flow under the effect of gas-solid coupling, this study will offer theoretical basis and technological support for the separating 
and cleaning of flax threshing materials based on "air flow cleaning and air-and-screen separation", and will improve the working performance of the double channel air-and-screen separation cleaner for flax threshing materials.

\section{Structure and working principle}

\subsection{Structure}

The separation cleaner for flax threshing materials is mainly composed of vibrating feeding system, three-stage vibration screening device, double channel residue collection device, dust removal device, vibrating frequency control system, threshing material discharge boxes and transmission device. The structure of the device is shown in Figure 1.
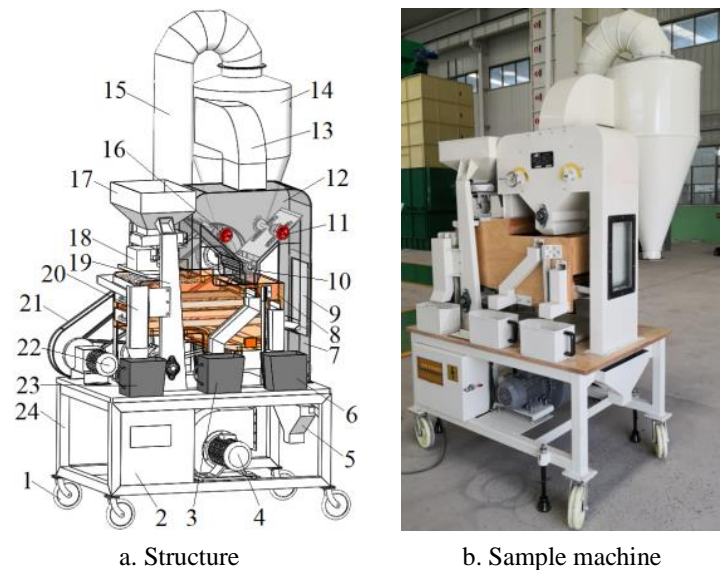

b. Sample machine

1. Walking wheel 2. Control box 3. Material discharge box III 4. Centrifugal fan 5. Flax grain discharge device 6. Material discharge box II 7. Rear air duct 8 . Three-stage vibrating screen box 9. Material observation window 10. Residue removal device 11. Air volume adjustment handle at the rear air duct 12. Residue collection chamber 13. Suction pipe 14. Cyclone dust collector 15. Fan duct 16. Air volume adjustment handle at the front air duct 17. Feeding hopper 18. Vibration feeding device 19. Support frame of the feeding hopper 20. Discharge channel of the first-level sieve 21. Belt drive I 22. Motor 23. Material discharge box I 24. Body frame

Figure 1 Structure of the double channel air-and-screen separation and cleaner for flax threshing materials

The amplitude of the vibration feeding device, vibration frequency of the three-stage sieve box could be adjusted by the sample machine control box. The meshes of the three-stage vibration sieve are composed of a first-stage slot hole sieve, a second-stage round hole sieve, and a three-stage slot hole sieve from top to bottom. The residue collection device has front and rear double air ducts, whose air volume adjustment handle can be applied to adjust the separating and cleaning effect of the flax threshing materials. The duct removal device and residue collection chamber are connected by the suction pipe.

\subsection{Analysis of the working process}

During working process, the vibrating frequency control box is used to set the amplitude of the vibration feeding device and the vibration frequency of the three-stage vibrating screen box. First, the flax threshing materials are fed into the feeding hopper of the device, then the materials are transmitted forward in uniform distribution by the vibrating feeding device. At this time, when the materials are about to fall on the first-stage slot hole sieve, the front air channel of the residue collection chamber will suck out the residue that is much finer than flax seeds, then the rest of flax threshing materials through the first-stage slot hole sieve, the second-stage round hole sieve and the third-stage slot hole sieve. All kinds of impurities in the threshing materials are sieved, and under the inertia force of the reciprocating vibration of the sieve box and punching of the rubber ball, most capsules, stalks of different lengths and capsule shells among the threshing materials are discharged through their respective discharge channels. Then the left-behind flax seeds and a few short stalks are sent to the rear air channel of the residue collection chamber, and under the effect of vertical air flow, the short stalks are sucked into the residue collection chamber and discharged together with the fallen residue through the residue removal device. Under the effect of gravity, the clean flax seeds are collected by the seed collection device, while the dusts and residue staying in the residue collection chamber are sucked by the cyclone dust collector through suction pipe, and finally discharged by the dust and residue discharge device.

\section{Simulation-based mathematical model}

\subsection{Dispersed phase governing equation}

In the theory of discrete element, the establishment of rectilinear motion and rotation of particles conforms to newton's second law. In simulation calculation of separation and cleaning of flax threshing materials, first, the contact situation between grains in the computational domain is determined, then the acting forces, counterforces and displacement are determined based on newton's third law, and the new unbalanced force between adjacent particles produced by relative displacement is calculated based on newton's second law. The entire particle population is traversed by iterative calculation till the forces on particles become balanced, and Equations (1) and (2) are the dispersed phase governing equations of the flax threshing materials ${ }^{[10,11]}$.

$$
\begin{aligned}
m_{i} \frac{\mathrm{d} \vec{v}_{i}}{\mathrm{~d} t} & =\sum f_{i} \\
I_{i} \frac{\mathrm{d} \vec{\omega}_{i}}{\mathrm{~d} t} & =\sum M_{i}
\end{aligned}
$$

where, $m_{i}$ is particle weight, $\mathrm{kg} ; t$ is acting time, $\mathrm{s} ; \vec{v}_{i}$ is particle velocity, $\mathrm{m} / \mathrm{s} ; f_{i}$ is the force on the particles, $\mathrm{N} ; I_{i}$ is rotary inertia of particles, $\mathrm{kg} \cdot \mathrm{m}^{2} ; \quad \vec{\omega}_{i}$ is angular velocity of particles, $\mathrm{rad} / \mathrm{s} ; M_{i}$ is the torque on particles, $\mathrm{N} \cdot \mathrm{m}$.

\subsection{The principle of one-way coupling}

Since the 3D model of the double channel air-and-screen separation cleaner for flax threshing materials takes up a huge space, the three kinds of sieves have a great number of meshes, and the model of flax threshing materials are mainly non-spherical particles, these factors can directly affect the simulation speed of the computer and consume the calculation ability of the computer. While in actual operation, the proportion of volume fraction of materials in the flow field is relatively small (less than 10\%), posing insignificant influence on fluid domain, thus one-way coupling is more effective in simulation. One-way coupling can be realized through two methods: one is coupling between EDEM and Fluent, which can realize calculation of various forces on materials from the flow field (drag force, Magnus force, Besset force, pressure gradient force, pressure gradient force), but the phase-to-phase data transmission is slow and requires more time in simulation calculation. The other is transforming flow field data obtained in Fluent to body force and loading it to EDEM. The phase-to-phase force calculated by this method has limitation, but the exchange of phase-to-phase data can be completely carried out in EDEM, so as to increase the speed of simulation calculation. Considering to the methods above and based on actual working conditions of simulation, the second one-way coupling method was adopted for simulation calculation in this study. 
In the one-way coupling calculation of body force, first, the data of steady flow field of the residue discharge device and the cyclone dust collector is calculated by Fluent, then the velocity components of the three directions, $X, Y$ and $Z$, in the steady flow field are saved in the form of CGNS data, then the plugin of body force CFielQuery in the Particle Body Force of EDEM is loaded, and the CGNS data are loaded in the form of field data in Field Data Manager. The drag force and buoyancy of the flow field in particle phase can be obtained by calculating with the body force plugin CFielQuery.dll. First, the equivalent radius of particles can be obtained by Equation (3); then the sectional area of particles corresponding to equivalent radius and the Reynolds number of local flow field are calculated based on Equations (4) and (5), then the resistance coefficient of particles' motion in the flow field is obtained based on Equation (6), thus the drag force on the particles in the flow field can be calculated by Equation (7). At last, send the Equation (8) for drag force and buoyancy back to EDEM, and obtain the particle displacement by Equation (1).

$$
\begin{gathered}
R=\left(\frac{3 V}{4 \pi}\right)^{\frac{1}{3}} \\
S=\pi R^{2}
\end{gathered}
$$

where, $R$ is the equivalent radius of particles, $\mathrm{m} ; V$ is the volume of particles, $\mathrm{m}^{3} ; S$ is the sectional area of particles, $\mathrm{m}^{2}$.

$$
R_{e}=\frac{\rho v L}{\mu}
$$

where, $R_{e}$ is Reynolds number; $\rho$ is air density, $\mathrm{kg} / \mathrm{m}^{3} ; v$ is the characteristic velocity of the flow field, $\mathrm{m} / \mathrm{s} ; L$ is the characteristic length of the flow field, $\mathrm{m} ; \mu$ is the dynamic viscosity, $\mathrm{Pa} \cdot \mathrm{s}$.

$$
C_{D}=\left\{\begin{array}{l}
\frac{24}{R_{e}}, R_{e} \leq 0.5 \\
\frac{24\left(1.0+0.25 R_{e}^{0.687}\right)}{R_{e}}, 0.5<R_{e} \leq 1000 \\
0.44, R_{e}>1000
\end{array}\right.
$$

where, $C_{D}$ is the resistance coefficient.

$$
\begin{gathered}
F_{D}=\frac{1}{2} C_{D} S \rho v_{r}^{2} \\
F_{b}=\rho G V
\end{gathered}
$$

where, $F_{D}$ is the drag force on particles of threshing materials in the flow field during movement, $\mathrm{N} ; v_{r}$ is the velocity difference between particles and the fluid, $\mathrm{m} / \mathrm{s} ; F_{b}$ is the buoyancy on particles in the flow field during movement, $\mathrm{N} ; G$ is the particles mass, $\mathrm{kg}$.

\section{Model establishment and parameter setting}

\subsection{Model establishment and computing mesh division}

The 3D structural diagram of the double channel air-and-screen separation cleaner for flax threshing materials was drawn in Solidworks 2018, then it was simplified by deleting irrelevant components in the simulation process, as shown in Figure 2. Then the diagram was saved as ".x_t" in universal data format and imported into ANSYS workbench $16.0^{[12]}$.

In ANSYS workbench, the order fill was applied to extract flow field domain (Figure 3a), then mesh generation was applied on flow field domain in the mesh module. Patch conforming algorithm was adopted as the mesh generation algorithm, which had good degree of fitting for model structure. The minimum mesh size was set as $4 \mathrm{~mm}$, and the maximum mesh size was set as
$25 \mathrm{~mm}$, obtaining a total of 124602 unstructured tetrahedral meshes, as shown in Figure $3 b^{[12]}$.

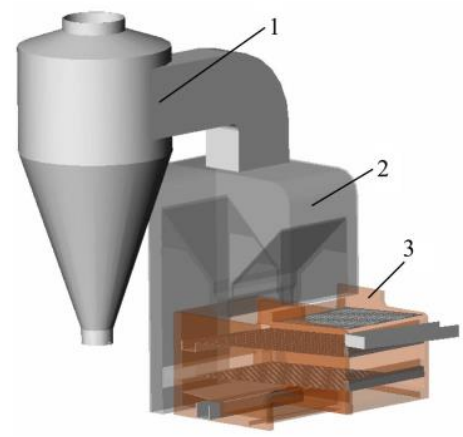

1. Dust removal device 2. Double channel residue collection device

3. Three-stage vibration sieving device

Figure 2 Simplified simulation model of the double channel air-and-screen separation and cleaner for flax threshing materials

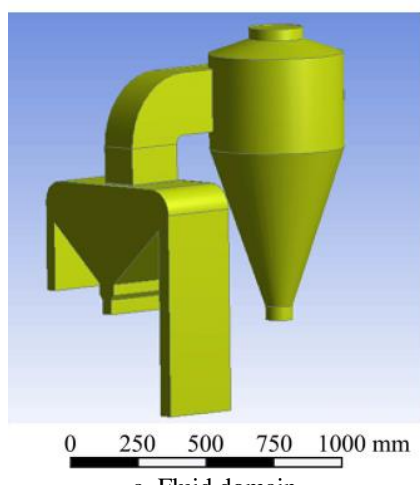

a. Fluid domain

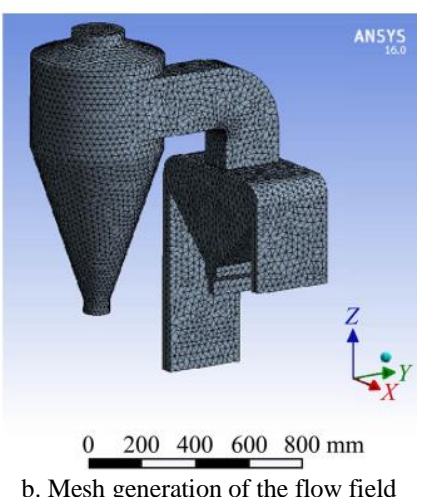

b. Mesh generation of the flow field
Figure 3 Fluid domain and mesh generation model of the separation cleaner

\subsection{Material model and parameter setting}

Based on the components of flax threshing materials, the simulation analysis includes five kinds of materials, which are flax seeds, capsule shells, capsules, short stalks and tiny impurities, with different shapes (Figure 4). Polyspherical particle filling method was adopted in EDEM to fit the shapes of different materials, among which flax seeds were aggregated by 18 spherical particles with dimension of $4.6 \mathrm{~mm} \times 1.5 \mathrm{~mm} \times 2.5 \mathrm{~mm}$ (length $\times$ width $\times$ height); capsule shells were aggregated by 9 spherical particles with dimension of $5.6 \mathrm{~mm} \times 3.0 \mathrm{~mm} \times 5.5 \mathrm{~mm}$ (length $\times$ width $\times$ height); capsules were aggregated by 2 spherical particles with dimension of $2.8 \mathrm{~mm} \times 3.1 \mathrm{~mm} \times 2.8 \mathrm{~mm}$ (length $\times$ width $\times$ height); short stalks were aggregated by 19 spherical particles with dimension of $15.4 \mathrm{~mm} \times$ $1 \mathrm{~mm} \times 1 \mathrm{~mm}$ (length $\times$ width $\times$ height); light impurities were set as spherical particles with radius of $0.8 \mathrm{~mm}$.

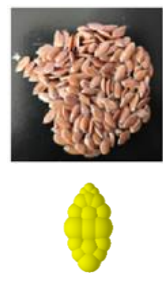

a. Flax seeds
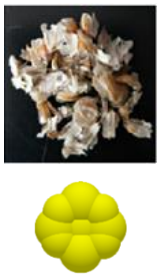

b. Capsule

$$
\text { shells }
$$
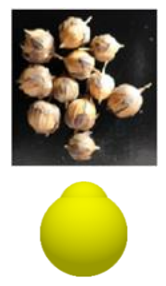

c. Capsules
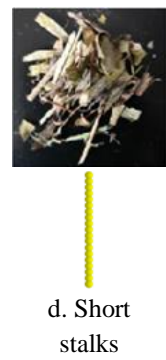
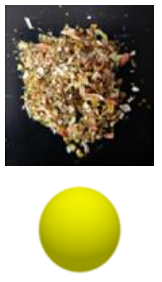

e. Light impurities
Figure 4 Different components of flax threshing materials and the discrete element model

According to the previous research results, the parameters of flax threshing material in EDEM are listed in Table $1^{[12]}$. The recovery coefficients of all materials were set as follows: particle-particle recovery coefficient was 0.20 for particle-stalk, 
0.20 for particles and capsule shells, 0.50 for particles and the wall of separation cleaner. The static friction factor between materials was 1.00 for particle-particle, 0.8 for particle-stalk, 0.80 for particles and the capsule shells, 0.80 for particles and capsules, 0.58 for particles and the wall of the separation cleaner; and the dynamic friction factor among all materials was set as 0.01 .

Table 1 Flax threshing material parameters in EDEM ${ }^{[12]}$

\begin{tabular}{cccc}
\hline Material & Poisson's ratio & Shear modulus/MPa & Density $/ \mathrm{kg} \cdot \mathrm{m}^{-3}$ \\
\hline Grains & 0.25 & 10 & 750 \\
Capsule shells & 0.25 & 12 & 100 \\
Capsules & 0.20 & 15 & 120 \\
Short stalks & 0.25 & 100 & 150 \\
Light impurities & 0.25 & 100 & 50 \\
Wall surface & 0.30 & 700 & 7800 \\
\hline
\end{tabular}

The feeding amount of the separation cleaner for flax threshing materials was set as $0.035 \mathrm{~kg} / \mathrm{s}$. According to the ratio of grain to straw in the flax threshing materials, after conversion, the material factory was located $80 \mathrm{~mm}$ from the inlet of the front air channel of the double channel residue collection device, generating 500 counts/s flax capsules, 1500 counts/s seed grains, 2000 counts/s short stalks, 2000 counts/s capsule shells and 500 counts/s light impurities. Different vibrating screens and screen boxes kept the same motion status in operation. Thus by merging the geometric objects with the same motion status in the simulation, the vibration amplitude in feeding was set as $16.5 \mathrm{~mm}$, and the vibration frequency of the screen box was set every $1 \mathrm{~Hz}$ among the range of 1-6 Hz. In order to ensure the consistency between the inclination angle of the vibration screen and actual situation, vibration direction was at an angle of $6^{\circ}$ with the horizontal plane, and the simulation time step was $1.25 \times 10^{-6} \mathrm{~s}$. The simulation lasted for $9 \mathrm{~s}{ }^{[9]}$.

\subsection{Coupling parameter setting of the model}

In the analysis and calculation by FLUENT, air was set as fluid medium with density of $1.2 \mathrm{~kg} / \mathrm{m}^{3}$ and viscosity of $1.8 \times 10^{-5} \mathrm{~Pa} \cdot \mathrm{s}$. The inlet boundary wind velocity of the front air duct is $1.60 \mathrm{~m} / \mathrm{s}$, and the outlet boundary wind velocity of the rear air duct is $4.40 \mathrm{~m} / \mathrm{s}$ with the double channel residue collection device. Standard $k-\varepsilon$ was taken as the turbulence model for transient calculation. The wall surface of the suction pipeline and the cyclone dust collector is non-slip wall. The pressure-based Semi-Implicit Method for Pressure Linked Equations (SIMPLE) algorithm was applied to solve the velocity field and the pressure field. The momentum term was in second order upwind scheme. The turbulent flow kinetic energy and turbulent dissipation rate were in the first-order upwind scheme with residual accuracy of $10^{-3} \mathrm{~s}^{[13]}$

\section{Simulation process and result analysis}

\subsection{Migration law of threshing materials in separation and cleaning}

Based on existing researches, the optimal working parameters of the double channel separation cleaner for flax threshing materials were obtained. The vibration frequency of the screen box was set as $2 \mathrm{~Hz}$, and air volume was set at the second gear, the air volume at the rear air channel was set at the 4.5 gear. The components of flax threshing materials (grains, capsule shells, capsules, short stalks and light impurities) were produced at an initial speed of $0 \mathrm{~m} / \mathrm{s}$. The migration process and law of the threshing materials were simulated. When the simulation process became stable, the velocity vector distribution of air volume in the double channel residue collection device and the cyclone dust collector was analyzed. Figure 5 shows that the air volume distribution in the two devices is reasonable with suitable air velocity vector, showing that the established simulated working model is correct ${ }^{[13-15]}$.

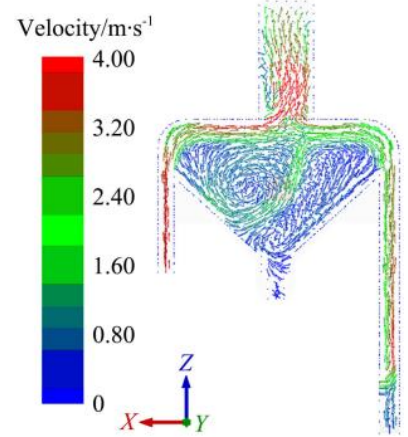

a. Air velocity vector distribution in the $b$. Air velocity vector distribution double channel residue collection device

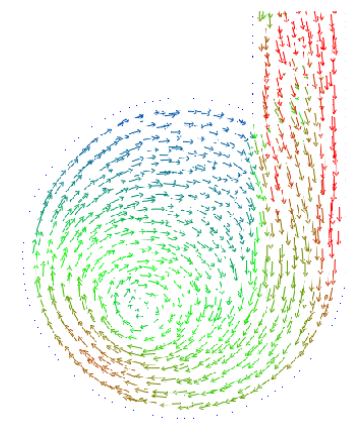

in the cyclone dust collector
Figure 5 Air velocity vector distribution of the double channel residue collection device and cyclone dust collector

During $t=0.15-9.00 \mathrm{~s}$, the separating and cleaning process and migration law of flax threshing materials in the double channel air-and-screen separation cleaner under the optimal parameters are shown in Figure 6. Since CFD-DEM coupling was started under the condition of convergent and stable flow field, from $t=0.15 \mathrm{~s}$, the EDEM numerical simulation was approximate to the working status of the double channel air-and-screen separating and threshing device for flax threshing material (Figure 6a). When $t=0.55 \mathrm{~s}$, the flax threshing materials on the first-stage slot hole sieve were distributed in three parts. Some light impurities with much lower floating velocity than flax seeds were first absorbed into the double air channel residue collection device and entered into the residue collection chamber. Meanwhile, under the reciprocating screening of the third-stage vibration sieve device, the capsules and long stalks stayed on the first-stage screen, and the other threshing materials fell on the second-stage round hole sieve, as shown in Figure $6 \mathrm{~b}$. When $t=0.95-1.35 \mathrm{~s}$, the material flow field at the front air channel of the double channel residue collection device became steady, and the absorbed seed grain, capsule shells and short stalks were continue to roll over, and gradually subsided. At this time, the long stalks and capsule shells were separated to the second-stage sieve, while the materials mainly including seed grains fell on the third-stage sieve. As shown in Figure 6e-f, when the light impurities in the residue collection chamber accumulated to a certain amount, they entered into the cyclone dust collector through the suction pipe. In this process, the materials were subject to gravity, pressure gradient force, drag force, spinning lift force and the striking force between the wall surfaces of the residue collection chamber and the cyclone dust collector, thus the materials spiraled down to the residue discharge device. In this way, the light impurities were separated. When $t=3.95-6.50 \mathrm{~s}$, the flax seeds and a tiny amount of short stalks on the thrid-stage slot hole sieve entered into the rear air channel of the residue collection device. Affected by gravity, the full flax seeds fell into the material discharge box. At the same time, a few other materials entered into the residue collection chamber through the rear air channel. When $t=4.50-6.50 \mathrm{~s}$, the material quantity in the flax separation cleaner kept stable. After threshing material entered into the device, different components can be separated and cleaned under influence of high-speed air flow in the front and rear air channels and the reciprocating screening of the three-stage sieving device. The separation and cleaning of different material 
components were realized in different working areas. When $t=8.00-9.00 \mathrm{~s}$, the materials piled up on the three-stage vibration sieve device gradually were flatten. Among the materials, the capsules and long stalks slid backward on the first-stage sieve and were discharged through the discharge channel of the first-stage sieve; capsule shells and short stalks slid forward on the second-stage sieve and were discharged through the discharge channel of the second-stage sieve; flax seeds also slid forward and were discharged through the discharge channel of the third-stage sieve. Therefore, other than the feeding quantity of threshing materials and vibration amplitude, the vibration frequency and air

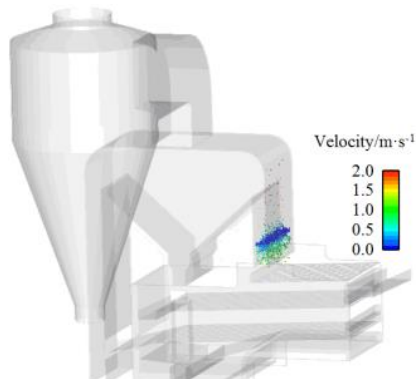

a. $0.15 \mathrm{~s}$

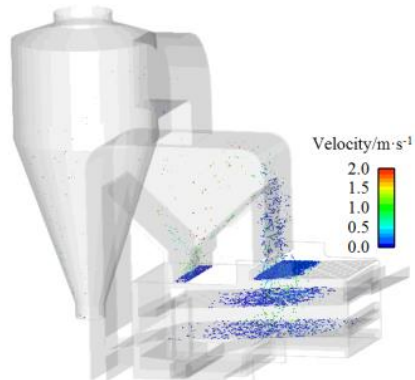

e. $2.15 \mathrm{~s}$

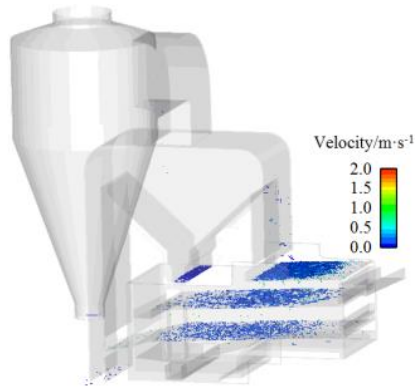

i. $5.50 \mathrm{~s}$

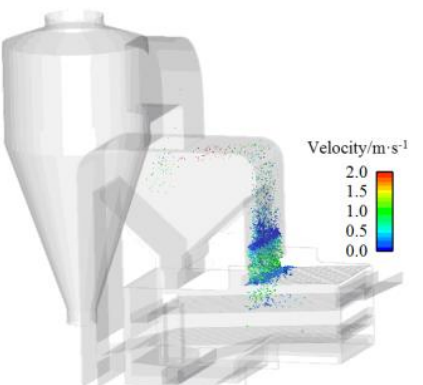

b. $0.55 \mathrm{~s}$

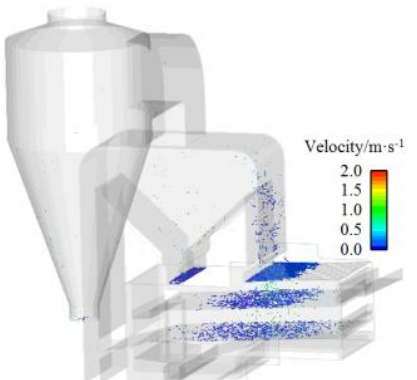

f. $2.55 \mathrm{~s}$

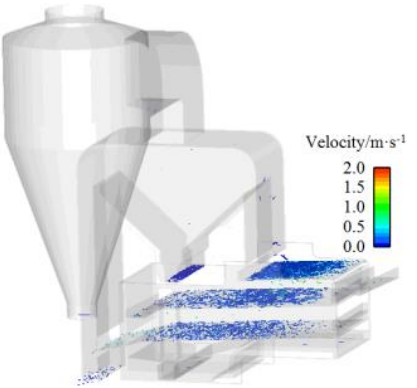

j. $6.50 \mathrm{~s}$

volume at the front air channel were very important to the working performance of the double channel air-and-screen flax seed separation cleaner. In order to improve the working performance of the sample machine, it is necessary to analyze the distribution pattern of materials in simulating the separation and cleaning of flax threshing materials, and to study the distribution amount of the components in the different areas of the separation cleaner, as well as their motion velocity ${ }^{[16-18]}$. After simulation of separation and cleaning, the results were calculated and analyzed, and the grain cleaning rate after numerical simulation was $91.32 \%$ with total separation loss of $2.51 \%$.

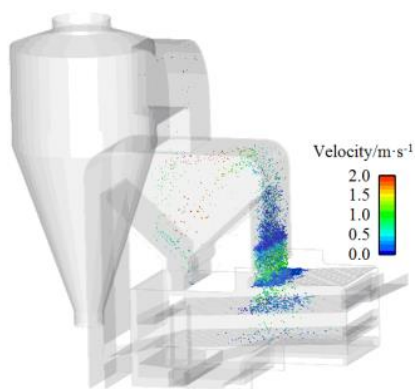

c. $0.95 \mathrm{~s}$

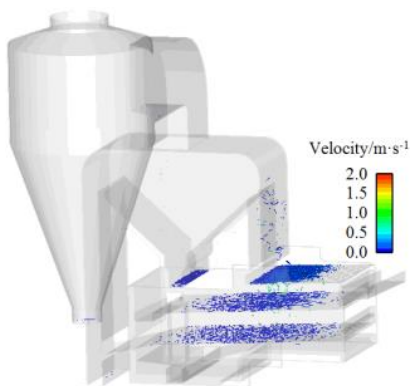

g. $3.95 \mathrm{~s}$

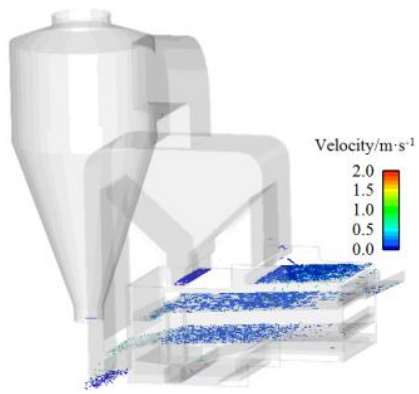

k. $8.00 \mathrm{~s}$

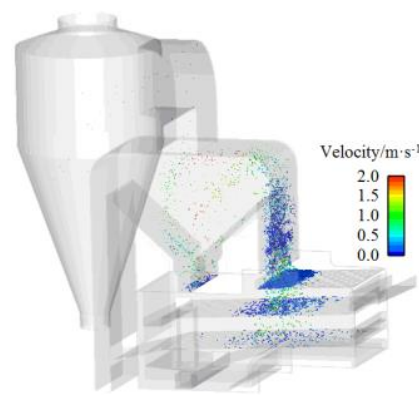

d. $1.35 \mathrm{~s}$

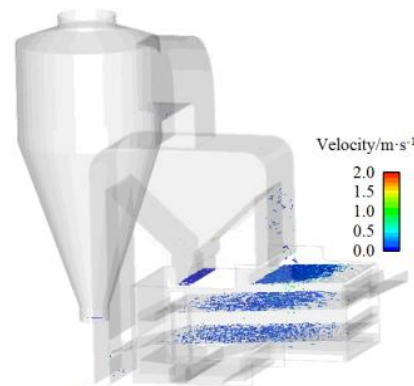

h. $4.50 \mathrm{~s}$

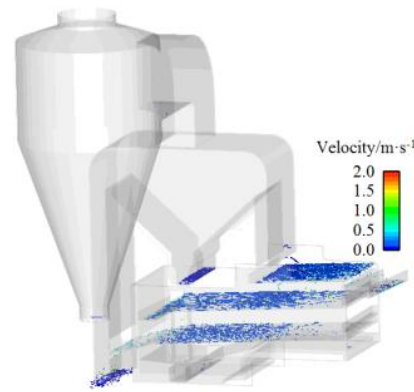

1. $9.00 \mathrm{~s}$

Figure 6 Separating and cleaning process of flax threshing materials in the double channel air-and-screen separation cleaner

\subsection{Material separation trajectory on the vibration sieve device}

Figure 7 shows the migration trajectories of main components of flax threshing materials at $t=9.00 \mathrm{~s}$ on the sieves of the three-stage vibration sieve device. Figure 7 a shows the motion trajectories of capsules and long stalks after they were separated by the first-stage slot hole sieve. Under the action of screening inertia, the two components slid backward in corrugated movement on the sieve and fell into the discharge channel of the first-stage sieve.

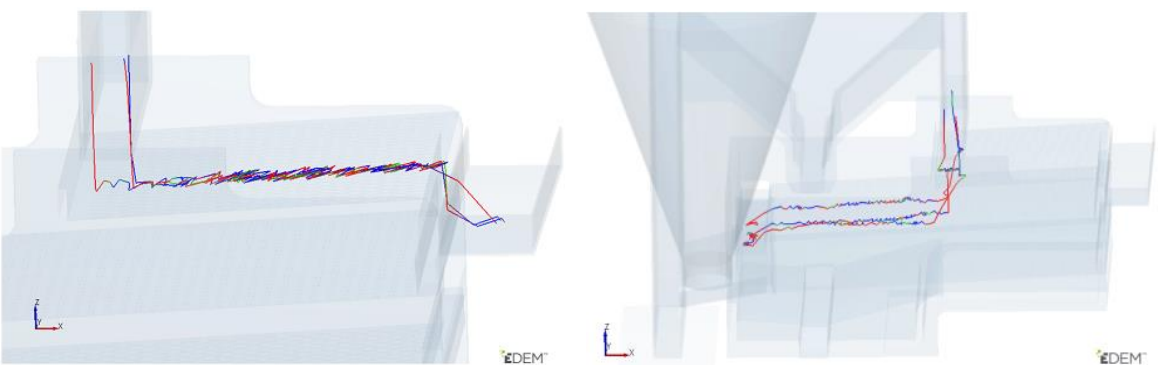

a. Separating trajectory of capsules and long stalks on b. Separating trajectory of short stalks and capsule shells the first-stage sieve on the second-stage sieve

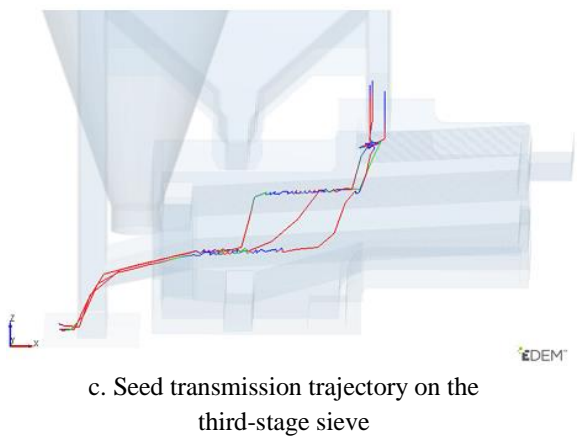

Figure 7 Material migration trajectory on the three-stage vibration sieve device 
Figure $7 \mathrm{~b}$ shows the motion trajectories of capsule shells and short stalks after they were separated by the second-stage round hole sieve. Under the action of screening inertia, the two components slid forward in curve shape and fell into the discharge channel of the second-stage sieve. The material separation and migration trajectory was relatively flat and smooth, showing that the setting of vibration frequency of the three-stage vibration sieve device was reasonable, and did not cause bouncing of the materials. After separating small capsule shells and a few short stalks by the third-stage slot hole sieve, the transmission trajectory of seeds toward rear air channel of the double channel residue collection device is shown in Figure 7c. It can be obtained after analysis that, the effective sieving areas of flax seeds on the second-stage and third-stage sieves equaled to each other, and both were higher than that on the first-stage sieving area. This is the reason for the lower length of the first-stage sieve than the other sieves in the design process.

\subsection{Material separating trajectories in the double channel} residue collection device

Preliminary studies show that, among the devices of the sample machine, the double channel residue collection device contains the most quantity of components of the threshing materials (seeds, short stalks, capsule shells and light impurities). Therefore, analyzing the motion trajectories of threshing materials in the double channel residue collection device could help detect and optimize the structure of the device. As shown in Figure 8a, blue streamlines represent the migration trajectories of short stalks, purple streamlines stand for the migration trajectories of capsule shells, green streamlines stand for that of flax seeds; while black streamlines stand for that of the rest light impurities. It can be seen that the migration trajectories of the components of the threshing materials are complicated. Therefore, the migration law of each component was studied respectively, as shown in Figures 8b-8d.

Figures $8 \mathrm{~b}$ and $8 \mathrm{c}$ show that, both the absorbed capsule shells and short stalks in the double channel residue collection device had the trajectory of parabola. Besides, their trajectories were similar to each other and they directly fell into the residue removal device, indicating that the two components were similar in mass, only some tiny capsule shells collided with the wind volume adjustment panel of the rear air channel and then fell into the residue removal device. Figure $8 \mathrm{~d}$ shows the migration trajectory of flax seeds. Similar to capsule shells and short stalks of flax, the seeds also had the trajectory of parabola. However, since the flax seeds had greater mass and small windward area, and the horizontal displacement was short, the seeds fell onto the wind volume adjustment panel of the front air channel and rolled into the residue removal device. The migration trajectory in Figure 8e shows that the light impurities were whirling and floating in the top area of the residue collection chamber after absorbed into the chamber. Therefore, it is reasonable to fix the suction pipe on top of the residue collection chamber. It can be concluded after the analysis above that the components of the materials had similar migration trajectories, which revealed the fact that the components of the flax threshing materials had little differences and were difficult to be separated and cleaned.

\subsection{Trajectory of separation of light impurities in the dust removal device}

As shown in Figure 9, when the light impurities are whirling and floating in the top area of the residue collection chamber, the high speed air stream in the suction pipe instantly absorbs them into the cyclone dust collector, and makes them spiral down into the residue discharge device. In this way, the separation of light impurities was finished in the fine and deep processing of flax seeds ${ }^{[19]}$.

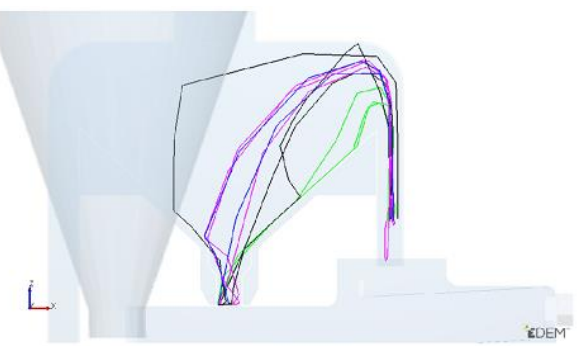

a. Migration trajectories of the threshing materials in the double channel residue collection device

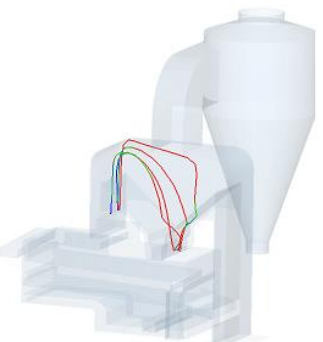

b. Migration trajectory of capsule shells in the device

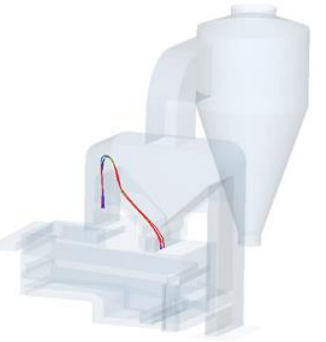

d. Migration trajectory of seeds in the device

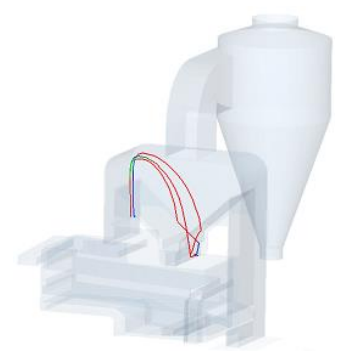

c. Migration trajectory of short stalks in the device

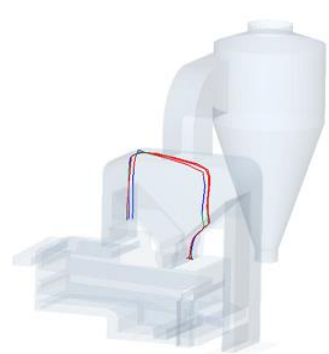

e. Migration trajectory of ligh impurities in the device
Figure 8 Material separating trajectories in the double channel residue collection device

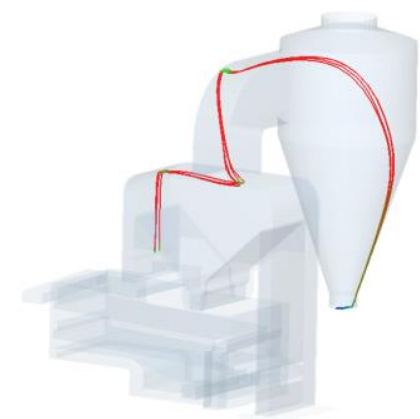

Figure 9 Trajectory of separation of light impurities in the dust removal device

\subsection{Material distribution on the sieves of the vibration sieve} device and in the residue discharge passage

Figure 10 shows the distribution of all components of the flax threshing materials on the first-stage slot hole sieve, second-stage round hole sieve and third-stage slot hole sieve, respectively. On the first-stage sieve, there are mainly capsules, capsule shells, short stalks, and flax seeds. Figure 10a shows that, the flax capsules and some long stalks slide backward and tend to enter the discharge channel of the first-stage sieve for separation (Figure 11a). Figure $10 \mathrm{~b}$ shows that, there are mainly flax seeds and short stalks on the second-stage sieve. Among them, flax seeds are dispersed and in uniform distribution on the sieve. While short stalks slide forward with the reciprocating vibration of the sieve, and pile up gradually, 
finally they slide into the residue discharge passage of the second-stage sieve and get separated (Figure 11b). After separating a large amount of short stalks and capsule shells, the materials on the third-stage slot hole sieve are almost flax seeds (Figure 10c), together with a few crushed stalks. They are fed into the rear air channel of the residue collection device for second dedusting and separation, as shown in Figure 11c.

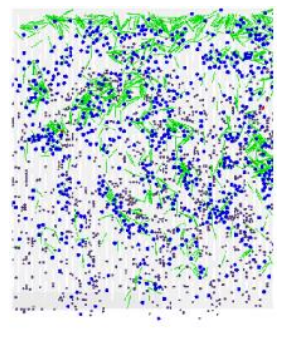

a. Material distribution on the first-stage sieve

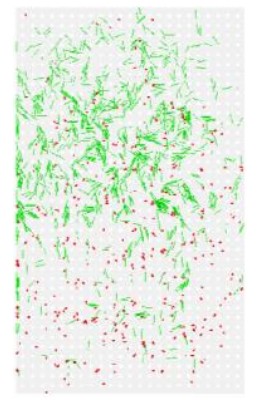

b. Material distribution on the second-stage sieve

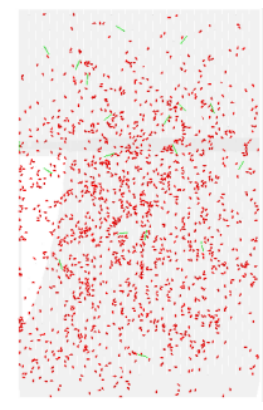

c. Material distribution on the third-stage sieve

Note: Blue material is flax capsules; Green material is flax stalks; Red material is flax seeds.

Figure 10 Material distribution on the sieves of the vibration sieve device

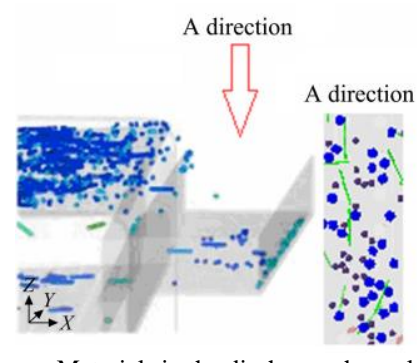

a. Materials in the discharge channel of the first-stage sieve

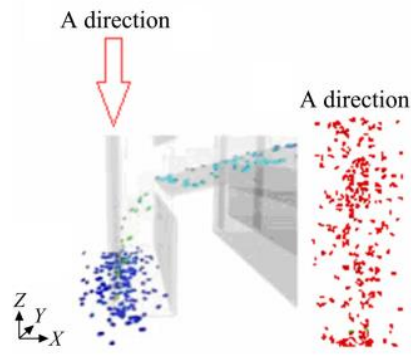

c. Seeds on the third-stage sieve Note: Blue material is flax capsules; Green material is flax stalks; Red material is flax seeds; Black material is capsule shells and light impurities.

Figure 11 Material distribution in the residue discharge passage

As shown in Figure 11d, the residue removal device separates multiple components, including flax short stalks, capsule shells, light impurities, a few seeds and a tiny amount of capsules. Therefore, the working performance of this device is one of the key factors influencing the content impurity rate and loss rate in cleaning of the device. Meanwhile, the threshing materials can be separated and cleaned for the second time.

5.6 Material quantity and velocity distribution in different regions of the separation cleaner

Material migration and retention in each areas in the device after separation and cleaning is one of the most important performance indicators that influence cleanliness of flax seed harvesting. Therefore, it is necessary to analyze the quantity and moving velocity of the components of material from region 1 and region 5 under influence of solid-gas flow (the distribution areas are shown in Figure
12), to find out the influencing factors for retention of components in the threshing materials ${ }^{[12]}$.

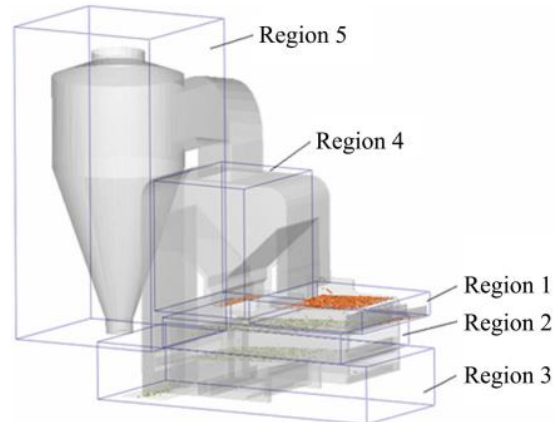

Figure 12 Different moving areas of flax threshing material in separation and cleaning process

The variation curves of quantity of components of flax threshing materials over time in different areas are shown in Figure 13. Figure 13a shows that after separating and cleaning in 5 regions of different devices, the flax seeds are concentrated within region 3, the third-stage sieve, and gradually pile up. Meanwhile, in region 4 , the residue removal device, there are some retained flax seeds, which is the key factor that affects the loss rate in cleaning of the device. Due to the type of the three-stage sieve, the short stalks and other materials enter into the first-stage sieve and are separated on the second-stage sieve. Since the short stalks are relatively long and heavy, few of them would enter into the region 3 , the third-stage sieve, and region 4 , the residue removal device (Figure 13b). As shown in Figure 13c, when three-stage vibration sieve device, and air volume of front and rear air channels were adjusted to an appropriate level, the flax capsule shells were in uniform and steady distribution in region 1 , the first-stage sieve. With the continuous operation of the machine, after $2 \mathrm{~s}$, most flax capsule shells formed a steady particle flow and entered into the double channel residue collection device through the front air channel, and were absorbed by the negative pressure air flow from the suction pipe, some fragments of capsule shells entered into the cyclone dust collector. It can be observed in Figure 13d that, after $1 \mathrm{~s}$ of simulation, some flax capsules gradually emerged in the residue removal device of region 4 , and the number of capsule particles became stable with the change of time. This part is mainly composed of small-sized shriveled capsules with smaller number of single granules or after incomplete threshing. Their floating velocity was lower than normal capsules, thus, they would be easily absorbed by adjusting the air volume of the front air channel. After screening by the first-stage sieve and the effect of the front and rear air channels of the double channel residue collection device, the light impurities in the region 4 first piled up, then reduced. The reason was that when light impurities accumulated to a certain amount, most of them were absorbed into the cyclone dust collector. Therefore, after $1.4 \mathrm{~s}$, the light impurities within the cyclone dust collector gradually increased and then became steady.

The variation curves of migration speed of components of flax threshing materials over time in different areas are shown in Figure 14. Figures $14 \mathrm{a}-14 \mathrm{c}$ showed that, the variation of migration speed of flax seeds, short stalks and capsule shells on the three stages of vibration sieve device were basically consistent. The migration speed of the three components kept within the range of 0.80 $1.50 \mathrm{~m} / \mathrm{s}$ after $3 \mathrm{~s}$. The three components made continuous irregular rotary motion in region 4 , the double channel residue collection device, and their migration speed had some fluctuations 
before $4 \mathrm{~s}$. After $5 \mathrm{~s}$, the migration speed of them reduced a little, and they fell into the residue removal device and were discharged. The flax seeds and capsule shells in region 5, the cyclone dust collector, were absorbed during simulation time of 2-3 s, and the maximum migration speed of flax seeds and capsule shells was $4.88 \mathrm{~m} / \mathrm{s}$ and $3.72 \mathrm{~m} / \mathrm{s}$, respectively. After that, the migration speed of them reduced and spiraled down in the cyclone dust collector, till they came to the dust and residue discharge device at last. Figure $14 \mathrm{~d}$ showed that the flax capsules kept a stable migration speed in region 1, the first-stage sieve, and could slide backward and get separated by the discharge channel of the first-stage sieve in order. The speed variation of them in region 4 ,

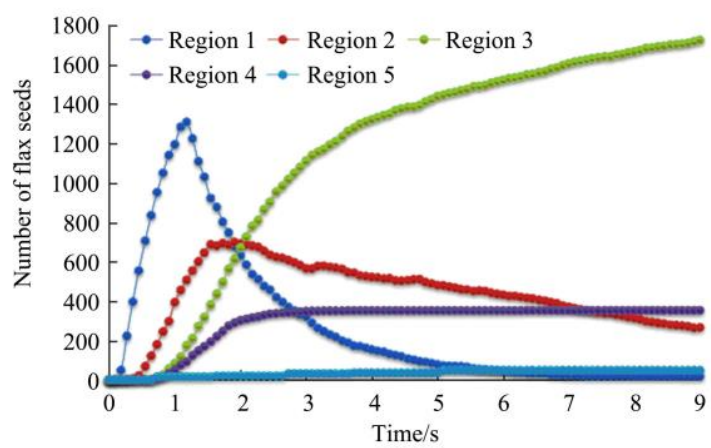

a. Quantity variation of flax seeds in different regions

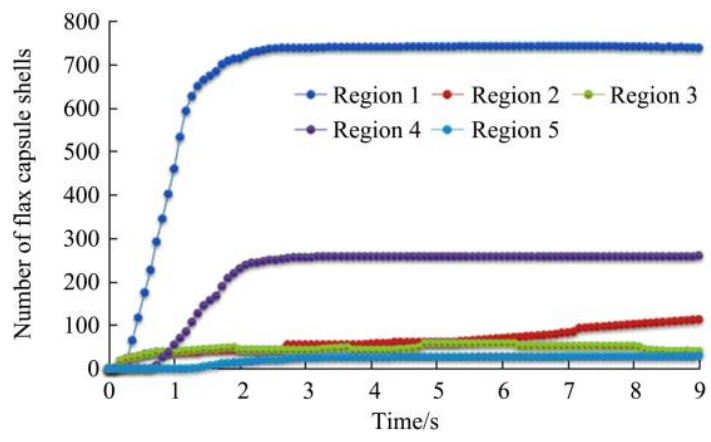

c. Quantity variation of flax capsule shells in different regions the double channel residue collection device, was basically similar to that of other material components, indicating that the disturbance of coupling airflow field on threshing materials was basically the same in the front and rear channels of the double channel residue collection device. Since light impurities are tiny, irregular in shape and very light, the variation laws of their migration speeds in region 1, region 4 and region 5 were irregular. The curves in Figure $14 \mathrm{e}$ showed that, when simulation time was $3.5 \mathrm{~s}$, the migration speed in double channel residue collection device and cyclone dust collector could reduce continuously, and this ensured the smooth discharge of them from the residue removal device and dust and residue discharge device.

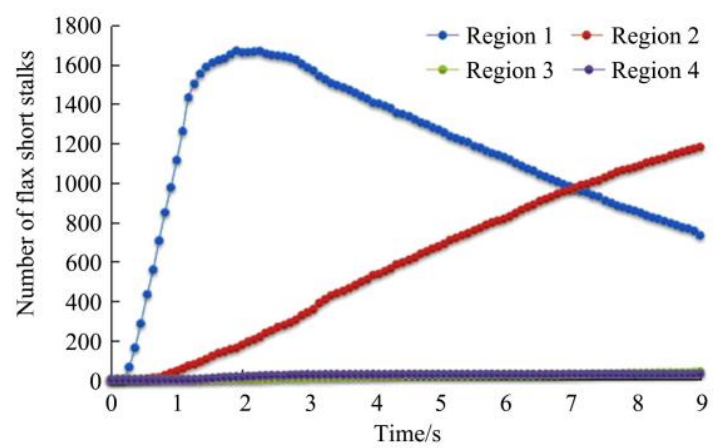

b. Quantity variation of flax short stalks in different regions

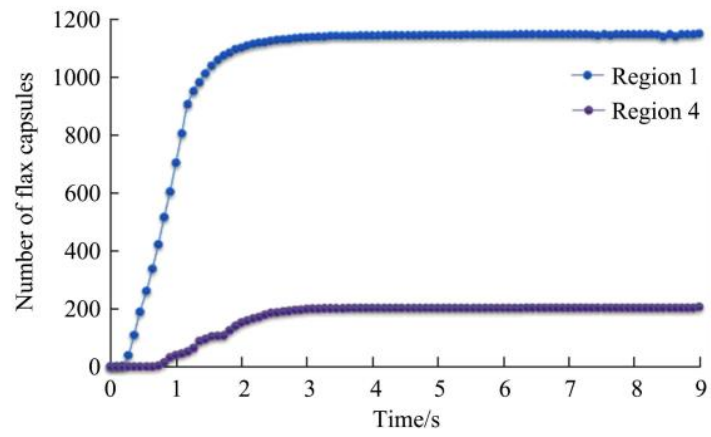

d. Quantity variation of flax capsules in different regions

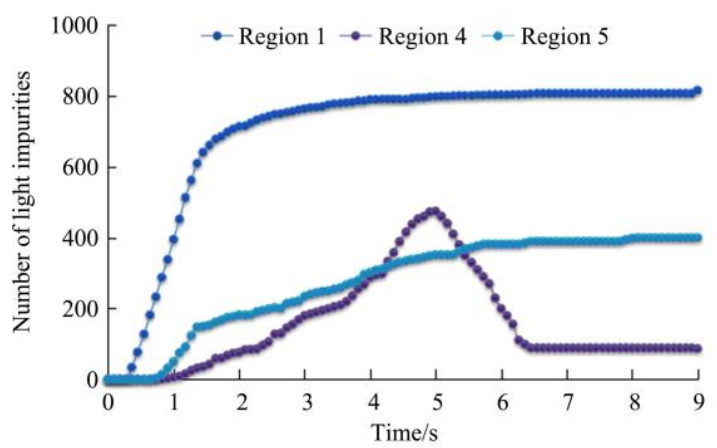

e. Quantity variation of light impurities in different regions

Figure 13 Variation curves of quantity of components of flax threshing material over time in different regions

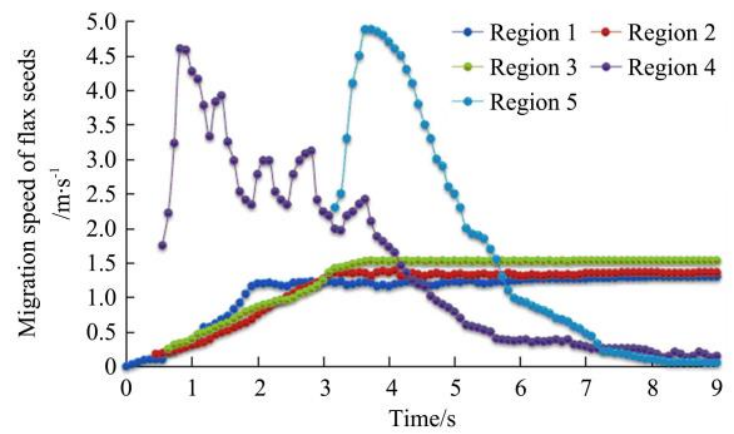

a. Migration speed of flax seeds in different regions

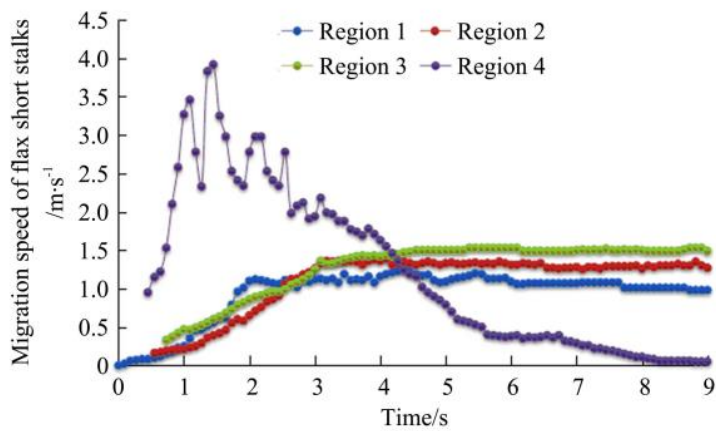

b. Migration speed of flax short stalks in different regions 


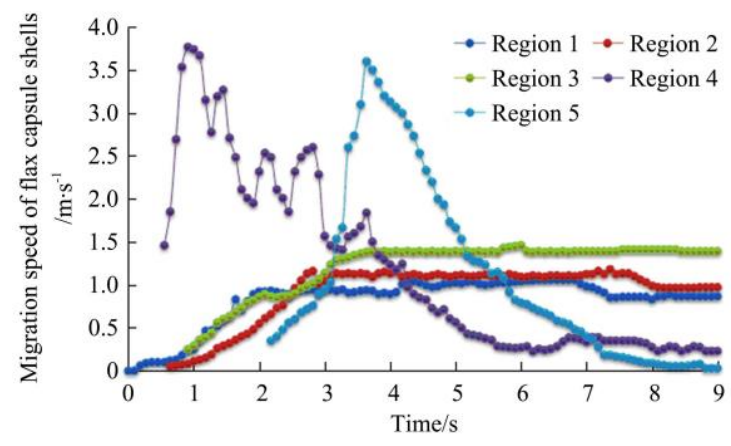

c. Migration speed of flax capsule shells in different regions

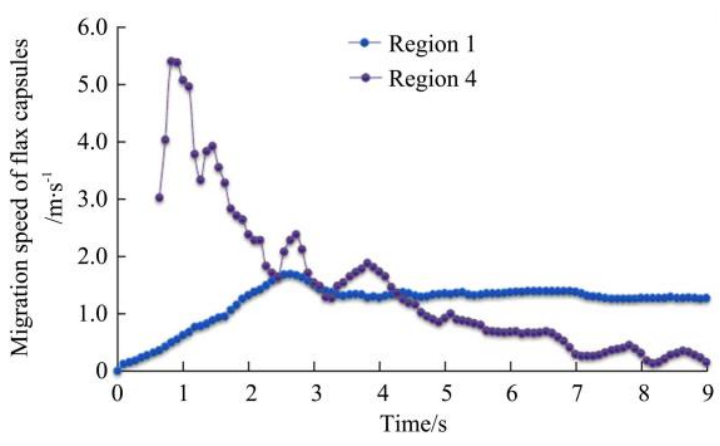

d. Migration speed of flax capsules in different regions

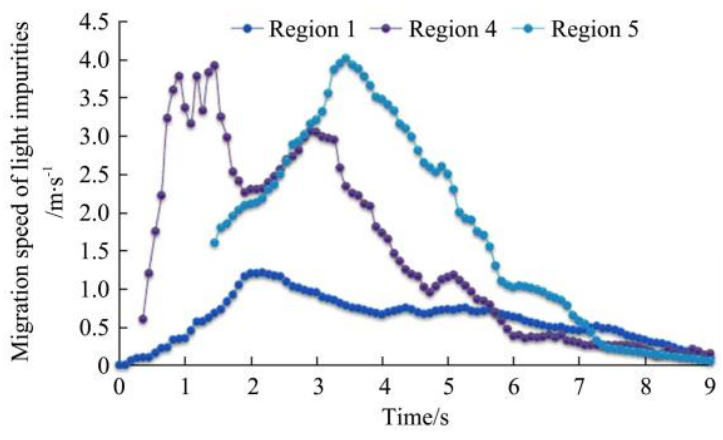

e. Migration speed of light impurities in different regions

Figure 14 Variation curves of migration speed of components of flax threshing materials over time in different regions

\section{Test verification}

In August 2019, the working performance test of the double channel air-and-screen separation cleaner for flax threshing materials was carried out at Gansu Huarui Agriculture Co., Ltd., which was the flax mechanization operation demonstration base of Gansu Agricultural University (Figure 15), and the simulation process was verified by tests. The test materials were selected from the threshing materials of Longya No. 14 during flax harvesting period. The average number of capsules per plant was 24.1 , average number of seed per capsule was 7.2 , the average thousand seed mass was $8.1 \mathrm{~g}$, the yield per plant was $0.95 \mathrm{~g}$, and the moisture content of the threshing material was $11.8 \%$. The working machine was checked by idling operation before the test. The vibration amplitude of the vibrating feeding system was set to $16.5 \mathrm{~mm}$, the inclination angle of the sieve surface of the three stages of vibration sieve device was $6^{\circ}$, and the vibration frequency of the screen box was between $0-2 \mathrm{~Hz}$. The air volume of the front air channel of the residue collection device was adjusted at gear 2, and that of the rear air channel was adjusted at gear $4.5^{[9]}$.

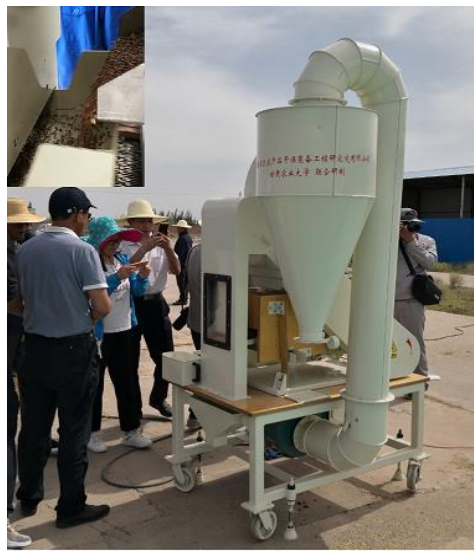

Figure 15 Test site of the double channel air-and-screen separation and cleaner for flax threshing materials
After the machine was running stably, flax threshing materials during the harvesting period were added into the feeding hopper. The test was conducted by continuously adjusting the vibration frequency of the screen box and the air volume of the front and rear air channels to determine the content impurity rate and loss rate in cleaning. At the same time, the working operation of the vibrating feeding system, the three-stage vibration sieve device, the residue collection device and the dust removal device and threshing material distribution were observed during the test.

It can be concluded through the distribution and output of the flax threshing materials at three stages of vibration sieve device (Figure 16) and distribution of separated materials in the residue discharge devices of the machine (Figure 17), material distribution on the sieves and discharge passages in the verification test and the simulated test (Figure 10 and 11) were consistent, showing that the established material model and parameter setting were basically reasonable. Verification test (Figure 18) results showed that the content impurity rate of the separation cleaner for flax threshing materials was $2.06 \%$ with total loss rate in cleaning of $3.08 \%$, and it could realize separation and cleaning of flax threshing materials

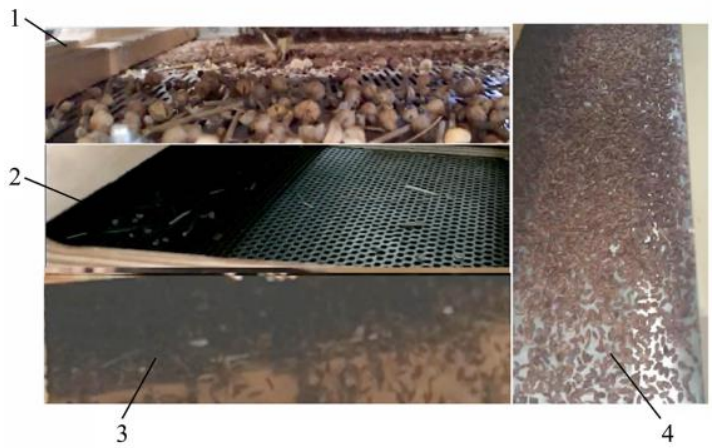

1. Threshing material distribution on the first-stage sieve 2 . Threshing material distribution on the second-stage sieve 3 . Threshing material distribution on the third-stage sieve 4. The threshed seeds on the third-stage sieve

Figure 16 Distribution and output of the flax threshing materials at three stages of vibration sieve device 
during harvesting period. Compared with simulated content impurity rate $(0.83 \%)$ and loss rate in cleaning $(2.66 \%)$, the test results were $1.23 \%$ and $0.42 \%$ higher, showing basic consistency between test results and simulation results, and the correctness of simulation results of the separation and cleaning process for flax threshing material based on gas-solid coupling theory.

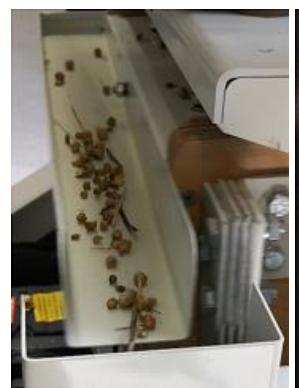

a. Separated materials from the first-stage sieve

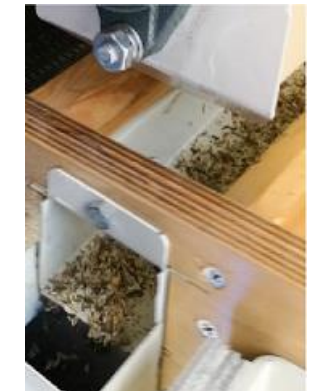

d. Separated materials from the residue removal device
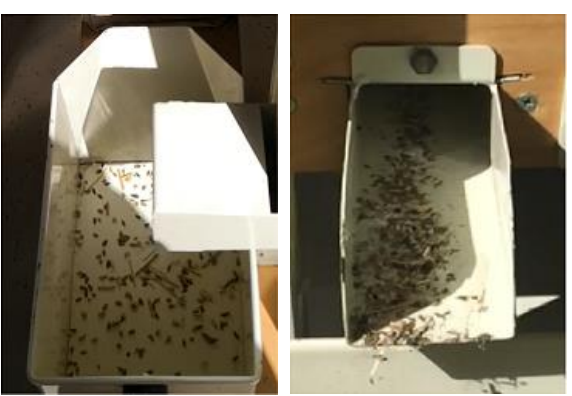

c. Separated materials from the third-stage sieve
Figure 17 Distribution of separated materials in the residue discharge devices of the machine
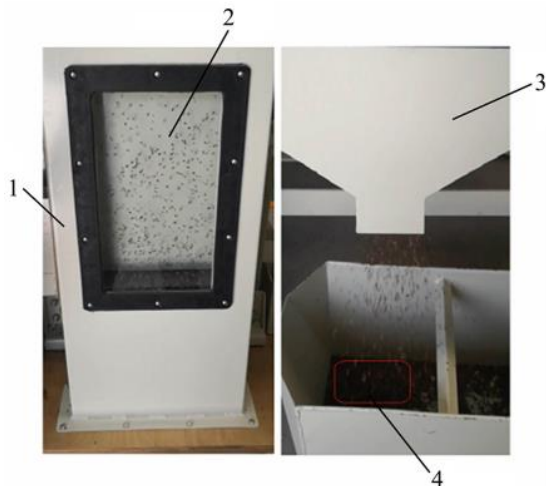

1. Rear air channel 2. Floating flax seeds 3. Flax grain discharge device 4. Flax seeds after cleaning

Figure 18 Verification test of the double channel air-and-screen separation cleaner for flax threshing material

\section{Conclusions}

1) After analyzing the working process of the flax separation cleaner, the dispersed phase governing equation of the flax threshing materials was established; based on the discrete element theory, the particle models of different components of the flax threshing materials was established; by applying the one-way coupling theory, a gas-solid coupling simulation model of the double channel air-and-screen separation cleaner for flax threshing materials was established.

2) CFD-DEM coupling method was adopted to do numerical simulation on the motion process of flax threshing materials in the separation cleaner, and air velocity vector distribution in the double channel residue collection device and the cyclone dust collector was obtained. By referring to the migration trajectories of the flax threshing materials in the vibration sieve device, double channel residue collection device and dust absorber, as well as the distribution of them in each device, the volume variation law, motion trajectories and variation trends of migration velocity of the components of flax threshing materials over time in different regions were explored.

3) Verification test was carried out by taking content impurity rate and loss rate in cleaning as the indexes of working performance of the flax separation cleaner, and it was found that the test results and simulation results were basically consistent. The test results (content impurity rate and loss rate) were $1.23 \%$ and $0.42 \%$ lower than that of simulation, showing that it was feasible to apply the gas-solid coupling theory and method to simulate the separating and cleaning of flax threshing materials.

\section{Acknowledgements}

The authors acknowledge that this work was financially supported by China Agriculture Research System of MOF and MARA (Grant No. CARS-14-1-28), Fuxi Young Talents Fund of Gansu Agricultural University (Grant No. Gaufx-03Y01), and Key Research and Development Project of Gansu Province (Grant No. 20YF3WA019).

\section{[References]}

[1] Wang L J, Li Y, Liang C, Ma J Q, Zhou W X. Motion law of maize mixture in cross air-and-screen cleaning device. Transactions of the CSAM, 2015; 46(9): 122-127. (in Chinese)

[2] Li H C, Li Y M, Gao F, Zhao Z, Xu Li Z. CFD-DEM simulation of material motion in air-and-screen cleaning device. Computers and Electronics in Agriculture, 2012; 88(6): 111-119.

[3] Dai F, Song X F, Zhao W Y, Han Z S, Zhang F W, Zhang S L. Motion simulation and test on threshed grains in tapered threshing and transmission device for plot wheat breeding based on CFD-DEM. Int J Agric \& Biol Eng, 2019; 12(1): 66-73.

[4] He Y, Bayly A E, Hassanpour A L. Coupling CFD-DEM with dynamic meshing: A new approach for fluid-structure interaction in particle-fluid flows. Powder Technology, 2018; 325: 620-631.

[5] Cleary P W. DEM simulation of industrial particle flows: case studies of dragline excavators, mixing in tumblers and centrifugal mills. Powder Technology, 2000; 109(1-3): 83-104.

[6] Wang L J, Feng X, Zheng Z H, Yu Y T, Liu T H, Ma Y. Design and test of combined sieve of maize screening. Transactions of the CSAM, 2019; 50(5): 104-113. (in Chinese)

[7] Gebrehiwot M G, Baerdemaeker J, Baelmans M. Numerical and experiment study of a cross-flow fan for combine cleaning shoes. Biosystems Engineering, 2010; 106(4): 448-457.

[8] Jiang E C, Sun Z F, Pan Z Y, Wang L J. Numerical simulation based on CFD-DEM and experiment of grain moving laws in inertia separation chamber. Transactions of the CSAM, 2014; 45(4): 117-122. (in Chinese)

[9] Dai F, Zhao W Y, Song X F, Shi R J, Liu G C, Wei B. Parameter optimization and experiment on separating and cleaning machine for flax threshing material. Transactions of the CSAM, 2020; 51(7): 100-108. (in Chinese)

[10] Liu L Y, Hao S Y, Zhang M, Liu D M, Jia F G, Quan L Z. Numerical simulation and experiment on paddy ventilation resistance based on CFD-DEM. Transactions of the CSAM, 2015; 46(8): 27-32. (in Chinese)

[11] Ma L C, Wei L B, Pei X Y, Zhu X S, Xu D R. CFD-DEM simulations of particle separation characteristic in centrifugal compounding force field. Powder Technology, 2019; 343: 11-18.

[12] Dai F, Song X F, Guo W J, Zhao W Y, Zhang F W, Zhang S L. Simulation and test on separating cleaning process of flax threshing material based on gas-solid coupling theory. Int J Agric \& Biol Eng, 2020; 13(1): 73-81.

[13] Wang S Y, Li H L, Wang R C, Wang X, Tian R C, Sun Q J. Effect of the inlet angle on the performance of a cyclone separator using CFD-DEM. Advanced Powder Technology, 2019; 30(2): 227-239.

[14] Tang Z, Li Y M, Xu L Z, Francis K. Modeling and design of a combined 
transverse and axial flow threshing unit for rice harvesters. Spanish Journal of Agricultural Research, 2014; 12(4): 973-983.

[15] Li Y, Xu L Z, Zhou Y, Si Z Y, Li Y M. Effect of extractions feed-quantity on airflow field in multi-ducts cleaning device. Transactions of the Chinese Society of Agricultural Engineering, 2017; 33(12): 48-55. (in Chinese)

[16] Wang L J, Wu Z X, Feng X, Li R, Yu Y T. Design and experiment of curved screen for maize grain harvester. Transactions of the CSAM, 2019; 50(2): 90-101. (in Chinese)
[17] Peng Z B, Doroodchi E, Moghtaderi B, Evans G M. A DEM-based analysis of the influence of aggregate structure on suspension shear yield stress. Advanced Powder Technology, 2012; 23(4): 437-444.

[18] Fu J, Chen Z, Tian L Q, Han L J, Ren L Q. Review of grain threshing theory and technology. Int J Agric \& Biol Eng, 2018; 11(3): 12-20.

[19] Jin X, Du X W, Gan BX, Ji J T, Dong X, Wang G X. Cleaning performance experiment of cyclone separating system in miniature combine harvester. Transactions of the CSAM, 2016; 47(5): 99-105. (in Chinese) 